\title{
AS TEORIAS DO TRABALHO DE HONNETH E UNGER: reconhecimento e produtivismo inclusivo
}

\author{
Ricardo Visser*
}

\begin{abstract}
Neste artigo, comparam-se duas escolas de pensamento da teoria social a partir do conceito de trabalho. Estendem-se, então, suas contradições internas. De um lado, a teoria do reconhecimento comporta um conceito de trabalho que se deixa definir por seu valor sociocultural e simbólico, inserido na hierarquia moral ocidental. Seu paradigma é a sociedade salarial e a regulação estatal da paridade das relações profissionais. Já o construtivismo institucional entende o conceito de trabalho como atividade produtiva destinada à inovação. Seu enquadramento teórico visa a recuperar a aliança entre progresso técnico-material com o incremento da experiência social dos indivíduos.

Palavras-chavE: Trabalho. Reconhecimento. Construtivismo institucional. Teoria social.
\end{abstract}

\section{INTRODUÇÃO}

Na teoria social contemporânea, encontramos duas tradições teóricas que recuperam a centralidade da categoria trabalho. Esse debate se inicia na década de 80 com Klaus Offe, que, por sua vez, aponta para a crescente tibieza da categoria trabalho como fator explicativo causal dos conflitos sociais, não mais sendo capaz de conferir sentido e unidade explicativa às interações sociais como dantes. No decorrer da segunda metade do século XX, por exemplo, o fortalecimento do setor de serviços e o incremento de posições de classe "intermediárias" - em nítido contraste com a tese da pauperização - dificultaram a aplicação tradicional dos conceitos marxistas. No Brasil, alguns autores de veio marxista vêm defendendo a centralidade do trabalho e da classe. Um dos seus expoentes mais célebres, cf. Antunes (2000), advoga a ideia de que os processos de reestruturação produtiva e de precarização são

* Universidade do Estado do Rio de Janeiro (UERJ). Faculdade de Direito.

Rua: São Francisco Xavier, 524. Maracanã. Cep: 20550-900. Rio de Janeiro - Rio de Janeiro - Brasil. ricardovis@gmail.com evidências empíricas que corroboram a centralidade da categoria trabalho.

Arrolamos, todavia, duas correntes de pensamento que escapam, cada uma a seu modo, aos preceitos teóricos ortodoxos do marxismo. De um lado, a teoria do reconhecimento, que busca, na categoria trabalho, um substrato normativo substancial a partir do qual é possível compreender tipos de injustiça, mas também formas factíveis de aprendizado e autonomia. Para esse ponto de vista, entende-se o trabalho como fator preponderante para gerar solidariedade e vínculos sociais indeléveis, na medida em que ele logra a formação da identidade pessoal dos indivíduos em contraposição direta à subjugação direta de dinheiro e poder (cf. Honneth, 2008).

Do outro lado, observamos uma teoria do trabalho, que, apesar de não negar a necessidade de gerar inclusão, questiona os impasses colocados por suas formas preponderantes na ordem produtiva contemporânea, perpetuada por uma configuração específica de arranjos institucionais. Sua principal questão é compreender como novos modos de organizar o trabalho podem estimular inovações produ- 
tivas, fazendo não apenas progredir a cultura material das nações, mas empoderando igualmente os indivíduos comuns em seu cotidiano. Aqui, há a associação entre emancipação individual e progresso material (Unger, 2001, p. 53). Seu objeto é a política transformadora, identificando, em boa parte do pensamento social, a ânsia de:

... reconstruir como razão aquilo que a história criou sob forma de contingência. Ele toma a organização estabelecida da sociedade como cenário até a próxima crise ocorrer e trata o mundo anterior à crise como se fosse para preservá-lo (Ibidem, p. xxiii).

Cabe notar, no entanto, que nenhuma das duas teorias reduz a categoria trabalho à sua função imediatamente econômica. Com isso, distanciam-se de uma abordagem comum à teoria da estratificação, na qual a categoria trabalho é reduzida à tríade ocupação, função desempenhada e faixa de renda. Sua intenção encontra maior ressonância na indagação sobre como as formas de trabalho auxiliam a caracterização de certa configuração institucional da divisão do trabalho. Tal enquadramento contribui, em contrapartida, para a reprodução de aspectos e características centrais encontrados no estilo e no modo de vida de indivíduos organizados em classes. Por seu turno, ela expressa, sobremaneira, como a organização

$\stackrel{\infty}{\mp}$ econômica e laboral exprime limites que conduzem ao empobrecimento da experiência so$\underset{1}{\perp}$ cial e individual, bem como erodem direitos adquiridos, responsáveis pela manutenção de i compromissos sociais de longo prazo.

Nas duas concepções, a esfera econômica não deve, portanto, ser compreendida apenas por sua fonte de legitimação mais aparente: a eficiência e a otimização na alocação de capital. Ao contrário, deve-se explicitar seu ancoramento numa ordem social histórica, na medida em que que ela contribui para a reprodução de relações de poder entre classes, assim como para a exclusão e a pobreza. Hegel, assim argumenta Honneth, já havia percebido que o mercado precisa de uma legitimação moral que "consiste em transformar o 'egoís- mo subjetivo' do indivíduo na disposição individual para atuar "em prol da satisfação das necessidades" de todos os outros" (Honneth 2008, apud Hegel, 1967, p. 55).

Não obstante, faz-se necessário mencionar uma fundamental distinção entre as duas vertentes: enquanto a teoria do reconhecimento inclina seus esforços analíticos para o diagnóstico crítico das injustiças do presente, a teoria do construtivismo institucional pende para a construção de alternativas e a imaginação programática, tendo como base a intensificação de formas experimentais de organização institucional da vida social. É uma resposta que visa a evitar estrangulamentos gerados por arranjos institucionais vigentes, que, naturalizando-se, podem provocar um vigoroso círculo vicioso de crises e reformas inócuas. A acepção de política transformadora adequa-se à construção programática paulatina e processual do futuro. É preciso planejar a mudança, ao invés de supor instaurá-la de uma vez; pensar o futuro de longo prazo primeiramente como futuro adjacente.

Procederei em duas seções: a primeira dedicada à teoria do reconhecimento e a segunda ao pensamento produtivista. Após a apresentação da argumentação, buscarei problematizar estrangulamentos teóricos para, então, vislumbrar uma possível síntese.

\section{RECONHECIMENTO E TRABALHO}

A teoria do reconhecimento tem, em sua expressão social filosófica, uma definição geral que se presta a aplicações em uma miríade de domínios da vida social. Seus expoentes maiores (Honneth, 2012; cf. Taylor, 1989) intentam distanciar-se de dois paradigmas dominantes da teoria crítica: a) da teoria pós-estruturalista do poder; b) da teoria procedimental da moralidade. A primeira conferia enfoque quase exclusivo à análise crítica da incorporação e subjetivação de mecanismos de dominação historicamente determinados, enquanto a se- 
gunda entendia que o processo de aprendizado político e democrático poderia ser assegurado através das garantias procedimentais de participação na formação da vontade política (Maciel; Torres, 2007, p. 183).

A definição do conceito de reconhecimento encontra sua expressão social filosófica na recuperação de Honneth da obra de juventude de Hegel. Em sua visão, o primeiro passo é reconstruir uma crítica do modelo de luta social dominante baseado na autopreservação (Honneth, 2008, p. 13). A premissa antropológica encontrada nessa tradição, com representantes como Hobbes e Maquiavel, presume o agente egocêntrico preocupado em maximizar sua ação em benefício próprio. Trata-se de uma ação estratégica tomada em seu caráter monológico, sem necessariamente ter a orientação a outrem como modus operandi constitutivo. Para Hegel, o ponto problemático dessa postura filosófica - alicerce do direito natural - consiste na centralidade ontológica do sujeito monológico isolado. Em seguida, transforma-se a consciência individual, maximizadora de seus interesses, em natureza humana. O conceito de liberdade adquire seu significado corrente no liberalismo, posto que o adensamento da vida pública (öffentliches Leben) passa a ser encarado como constrangimento de espaços de liberdade privados (private Freiheitsspielräume). Segundo Honneth (2008, p. 24), Hegel coloca essa acepção de ponta cabeça, já que a realização da liberdade individual é decorrente do robustecimento da vida pública.

Desse modo, todo tecido social é permeado por uma eticidade (Sittlichkeit), cujo apanágio principal é não se deixar conter totalmente pelo ordenamento jurídico do Estado e nem pelas convicções morais individuais. $\mathrm{Na}$ medida em que se configura como pano de fundo intersubjetivamente compartilhado de hierarquias morais, é possível concretizar avaliações normativas sobre a vida que vale a pena ser vivida. Em sociedades modernas, capazes de vínculos morais passíveis de revisão e redirecionamento, torna-se factível transfor- mar o processo histórico numa universalização de potenciais "morais" por meio do conflito coletivo. Eis aqui a ideia de que a História deve ser compreendida com referência a um patamar de aprendizado coletivo e à categoria de reconhecimento.

Honneth, então, procede demonstrando como o crime de roubo contém um significado normativo, tornando a dependência da identidade individual da comunidade objeto de um saber público. A definição social filosófica do reconhecimento corresponde a um salto cognitivo no qual se realiza

\begin{abstract}
... uma consciência "ideal", com referência à totalidade, no momento em que ela se entende noutra totalidade, isto é, noutra consciência; assim, é possível atingir, através do conflito, a experiência de Saber-se-em-outrem apenas porque foi plausível adquirir um saber através do ferimento mútuo de suas pretensões individuais (Honneth 2012, p. 49, apud Hegel 1967, p. 116, tradução nossa).
\end{abstract}

Nessa passagem, fica claro que a luta por reconhecimento repousa sobre uma intensificação do processo de socialização, por meio da descentralização das formas de experiência aprisionadas na consciência individual. A partir da explicitação de uma experiência intersubjetivamente compartilhada (saber adquirido do conflito), o conceito de reconhecimento pressupõe, acertadamente, que as ações, emoções e ponderações dos agentes tomem sempre o outro como referência. Por outro lado, o aspecto central da categoria de reconhecimento é sua alusão a certa simetria, paridade e reciprocidade em interações sociais. Ao reconhecer outrem como sujeito, confere-se um estatuto de humanidade a alguém ("ser alguém"), proporcionando-lhe a possibilidade de constituir autoestima e autorrelação prática positiva consigo.

Para a teoria crítica do reconhecimento, a categoria trabalho encontra sua força por ser um dos pilares da fundamentação normativa de um corpo social. Entretanto uma crítica da organização do trabalho pode ser apenas operada a partir de parâmetros normativos imanentes à troca de desempenhos, dado que 
uma forma laboral exprime a qualidade de sua contribuição produtiva com relação à divisão social do trabalho (Honneth, 2008, p. 51).

Se uma forma de trabalho deve ser enquadrada de acordo com sua contribuição produtiva, nem todos os trabalhos contribuem de igual maneira, de modo que não se pode usar um critério externo para avaliá-los. Isso evita não apenas anacronismos, como se valer do critério do trabalho artesanal (preponderante na pré-modernidade) para avaliar o industrial, como também uma equalização indevida das contribuições laborais. Assim sendo, só é possível encontrar critérios e medidas internas às próprias interações criticadas servindo como fundamentação de reivindicações e justificações racionais. Entretanto as condições normativas de reconhecimento do mercado (de trabalho) podem entrar em contradição consigo próprias, já que nem sempre elas garantem autonomia econômica às parcelas marginalizadas (Ibidem, p. 54-56). Honneth identifica esse processo de pauperização na tendência (contingente) do sistema capitalista à concentração de poder de mercado nas mãos de poucos agentes econômicos.

A partir do desenho geral sobre o fundamento normativo do trabalho, podemos delimitar entre duas fontes morais, que se codificam $\infty$ na esfera laboral: a dignidade e a autenticidade. ণ Na primeira delas, torna-se explicita a dimen-

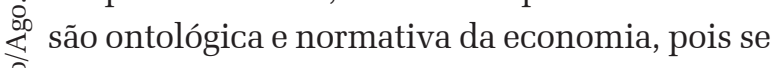
trata do direito, na ordem econômica moderna, de o indivíduo contribuir parcialmente para o bem-estar geral, obtendo, em contrapartida, um mínimo que lhe assegure a subsistência imedia$\dot{\infty}$ ta e futura. Materializa-se, aqui, o preceito da ¿ dignidade através da inclusão na sociedade saì larial, assim como na regulamentação justa das relações e condições de trabalho.

Essa fonte moral também foi cunhada como dignificação (Würdigung), ${ }^{1}$ uma vez que o trabalho é entendido como fator coleti-

${ }^{1} \mathrm{O}$ termo Würdigung, utilizado por Voswinkel, pode ser traduzido por dignificação, enquanto a categoria Würde, empregada por Honneth, significa dignidade. vo de produção (Voswinkel, 2013, p. 221). A sindicalização e a formação de categorias profissionais sob a forma de grupos de interesse exemplificam esse campo do reconhecimento, com sólida presença na formação do Estado de bem-estar social europeu no pós-guerra. Seu enquadramento corresponde à regulação institucional da paridade das relações profissionais e contratuais, para além de seu conteúdo formal e estritamente legal. Direitos sociais e salários indiretos, como o acesso universal a um sistema educacional e de saúde de qualidade, também contribuem fortemente para o apaziguamento das urgências materiais imediatas e futuras. Através do adensamento de vínculos de solidariedade no longo prazo, as expectativas das classes ameaçadas se estabilizam.

A ideia de dignidade e dignificação corresponde à autonomia econômica, cujo pilar é a subsistência, porquanto a contribuição econômica por uma realização laboral permite domar temporalmente necessidades e urgências econômicas básicas, tornando-as passíveis de serem supridas estavelmente. Ela conecta, portanto, uma dimensão existencial e material "de vida ou morte”, uma vez que a expansão do mercado de trabalho moderno incute a retração do recurso à subsistência, ainda comum em épocas de escassez no mundo rural. Por exemplo, Simmel (2009) já apontava para essa contradição psicológica na classe trabalhadora: por um lado, o dinheiro garante, através da troca, a liberdade pessoal de gastá-lo com o que se deseja; por outro, ele é limitado estruturalmente em suas finalidades de uso. Nesse caso, a liberdade pessoal da experiência vivida pode contradizer limitações estruturais.

Contudo a dimensão da dignidade econômica não consiste apenas da subsistência imediata, ao aplacar a impetuosa miséria material, mas implica igualmente a chance de tornar as práticas econômicas minimamente prospectivas (cf. Visser, 2015), ganhando acesso às estruturas temporais relativas ao futuro abstrato (cf. Bourdieu, 1977). O assalariamento é uma forma de garantir tais condições eco- 
nômicas, na medida em que a renda se estabiliza. Tal realidade não inclui boa parte dos trabalhadores informais desqualificados brasileiros, cuja renda geralmente congrega alta variabilidade e baixo volume (Visser, 2015, p. 51). Sob esse prisma, o acoplamento de condições estáveis com um volume confortável de práticas econômicas prospectivas - de propriedades rentáveis, como a transformação de poupança em investimento financeiro de longo-prazo (previdência privada, títulos de baixo risco, renda fixa e etc.), além de propriedades produtivas - conforma uma "porta de entrada" ao reconhecimento na esfera econômica, geralmente mediada por instituições financeiras e legais dominantes.

Ainda com relação à dignidade econômica, faz-se imperativo afirmar que o sentido propriamente econômico do trabalho, isto é, o valor real da renda, está diretamente ligado à mediação privada ou pública de serviços básicos como previdência, saúde e educação, de modo que o acesso a esses serviços se torna reduzido à capacidade de pagamento dos estratos sociais, embora possa ser encarado como um direito constitucional. A expansão efetiva desses direitos cidadãos impede a determinação nua e crua pelo dinheiro, circunscrevendo e delimitando os imperativos sistêmicos de atuação do mercado (Dutra, 2016, p. 78).

Um segundo desdobramento do conceito de dignidade toca particularmente formas de trabalho desqualificados em países onde vigora o capitalismo periférico, atreladas a profundas experiências de humilhação (cf. Maciel, 2014). O trabalho desqualificado - no qual flanelinhas, camelôs, empregadas domésticas, catadores de lixo, todo tipo de vendedores informais, guardadores de carros e outros estão envolvidos - incorre não apenas em pobreza material, que também possui forte carga ontológica, mas igualmente em experiências de humilhação e desrespeito.

Isso posto, importa considerar que essa forma de degradação social e moral ocorre porque o reconhecimento negado e a experi- ência de marginalização do trabalho informal desqualificado (ou até ilegal) operam uma desclassificação do desempenho em conjunto com a identidade pessoal do trabalhador. A troca de dinheiro por desempenho, libertando a esfera pessoal (cf. Simmel, 2009), torna-se embaçada. Acrescente-se o fato de que, por não terem o direito de contribuir significativamente para a reprodução material da coletividade daquela forma, quase todos não têm outra escolha senão desempenhar aquela ocupação socialmente desqualificada.

Por fim, a dignidade no trabalho também faz vicejarem as pré-condições da participação na esfera política (Maciel; Torres, 2007, p. 184-185). Para além de uma esfera pública livre e de um direito positivo, a participação cidadã autônoma pressupõe a emancipação do constrangimento direto de dinheiro e poder. A conexão entre trabalho, política e reconhecimento se nutre da insuficiência da mera garantia procedimental de direitos políticos, penetrando nos acordos pré-políticos condicionantes do empoderamento cidadão. Nesse caso, a fonte moral da dignidade econômica corrobora o processo de inclusão em outras esferas. Contudo os autores não argumentam - como o faz o marxismo tradicional - que a atividade produtiva proporcionaria acesso direto à consciência política (de classe). Trata-se de uma das pré-condições para a participação cidadã. É conveniente, então, pontuar que o respeito à teoria da diferenciação das esferas de valor é preservado, dado que a consciência política não é deduzida diretamente das relações de produção.

No acoplamento tácito da esfera laboral com outras, ainda poderíamos citar como a estabilização das urgências econômicas conduzem à atenuação da tensão entre trabalho por necessidade e planejamento racional da trajetória escolar. E também como o reconhecimento, na esfera da admiração (Bewunderung), isto é, da realização pessoal (cf. Voswinkel, 2013), beneficia o aprendizado do capital cultural na esfera familiar, visto que se trata de empregos 
em que o reconhecimento de competências intelectuais e educacionais desempenha um papel relevante na formação da identidade profissional. Em seu caso limite, desenvolve-se a socialização lúdica com a cultura letrada, mediada pela "curiosidade" no aprendizado da cultura legítima e sua forte carga afetiva. Frequentemente, seu lado disciplinar é cada vez menos mediado pela sanção direta. Disposições desviantes e transgressoras tornam-se passíveis de uma ressignificação expressiva (cf. Simmel, 1989) e até artística.

Seria factível argumentar que indivíduos mais propensos a desempenhar tal classe de profissões tiram proveito da acumulação geracional prévia da escolaridade familiar. Muito diferente é a apropriação da cultura letrada pelas classes subalternas, para as quais, comumente, leitura e escrita não rompem com sua finalidade funcional e meramente informativa. Não raro sua inserção ocupacional confirma tais circunstâncias.

Dessa maneira, a fonte moral da admiração estaria ligada à noção de diferenciação e individualização da realização laboral. Ela indica não apenas que, no labor, o trabalhador experimenta a circunstância de sentir-se "um ser destinado a tarefas", como pensou Hegel (Honneth, 2012, p. 61), mas como produtor criativo capaz

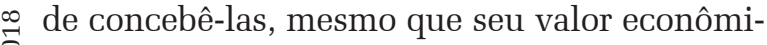
co não seja imediatamente apreciável. o que se manifesta em problemas motivacionais e demissões (Voswinkel, 2013, p. 223224). Consequentemente, a erosão de critérios institucionalizados e fixados da dignidade não coincide necessariamente com a "ausência de solidariedade", mas assinala seu câmbio em direção à admiração. Por conseguinte, deterioram-se vias coletivas de reconhecimento laboral, como sindicatos e categorias profissionais. $\mathrm{Na}$ esteira da deterioração do reconhecimento estável, as biografias normais (Ibidem, p. 219) escasseiam, além do revigoramento do setor de serviços e da ascendência do sistema financeiro sobre o capital produtivo. Concomitante a isso, diferenciam-se cada vez mais, como domínios funcionais distintos, trajetória profissional e posto de trabalho ocupado numa determinada etapa da vida (cf. Kühn; Wintzel, 2004).

Com isso, a retomada da realização pessoal no trabalho, associada à possibilidade de se tornar um trabalhador criativo e inovador, já nasce, de certa maneira, instrumentalizada. Se, por um lado, essa fonte moral tem como promessa uma retomada da importância da marca e da realização pessoal, em contraste com a padronização da linha de montagem taylorista-fordista, ela tende a criar um arremedo de autenticidade, ainda mantendo o poder das grandes decisões nos escalões administrativos superiores. A validade dessa premissa é ainda mais profunda em setores de baixa inovação da divisão do trabalho, nos quais o contexto pedagógico laboral permite apenas reavaliações e retoques pontuais das tarefas.

Outro tema que abarca tanto dignidade quanto realização pessoal concerne à incorporação do conhecimento chancelado pelo sistema de ensino como paradigma normativo da hierarquia moral ocidental do trabalho (Maciel; Dutra, 2007, p. 200). O conhecimento teria se tornado um fator de produção preponderante, não se confundindo com o saber (Ibidem, p. 201), muitas vezes adquirido na experiência laboral dentro um contexto pedagógico relativamente aberto, mas sem mediação com o sistema de ensino formal. Por outro lado, a 
associação entre mérito, recompensa e conhecimento omite as condições prévias desiguais de treinamento para o mercado de trabalho, ou seja, o acesso ao sucesso escolar em disciplinas que garantem bons empregos. Ao privilegiar esquemas cognitivos e procedimentos escolarmente aceitos, constrange-se, do mesmo modo, o espaço de aprendizado no local de trabalho, destacando claramente execução e planejamento.

A categoria trabalho recuperada pela teoria do reconhecimento enfatiza, sobretudo, o desvelamento de premissas normativas subjacentes à economia de mercado, em detrimento de sua definição meramente instrumental. Dentro de seu constructo teórico, assiste-se à propensão que demarca o valor coletivamente construído do desempenho laboral. Mais do que o valor meramente econômico, deve-se se perguntar pela estima cultural à qual um trabalho está atrelado. Pois essa

... circunstância, em meu ponto de vista, demonstra que as regras de distribuição não podem ser simplesmente derivadas das relações de produção, mas devem sim ser vistas como expressão institucional de um dispositivo sociocultural que determina qual grau de estima, atividades específicas ocupam em um determinado momento. Os conflitos sobre distribuição, contanto que eles não estejam meramente preocupados apenas com a aplicação de regras institucionalizadas, são sempre lutas simbólicas pela legitimidade do dispositivo sociocultural que determina o valor das atividades, atributos e contribuições [...]. Em resumo, é uma luta pela definição cultural sobre o que é que torna uma atividade socialmente necessária e valiosa (Honneth, 2007, p. 92-93).

Essa passagem mostra-nos a definição da categoria de trabalho não mais pelo seu valor diretamente produtivo, mas contrastado com um pano de fundo sociocultural determinante da sua estima. Trabalho seria, então, correlato de seu status (entendido como valor simbólico-cultural). Tal argumentação realça: a) o aspecto construído do valor das ocupações, na medida em que se baseia na estrutura comunicativo-simbólica e cultural da sociedade; b) a conjunção entre luta simbólica e material, já que demandas por igualdade econômica tocam o âmago e o desdobramento dos estilos de vida como um todo (identidade); c) que a divisão do trabalho social não é apenas composta por setores diretamente ligados à produção material, ou às finanças. Nem mesmo o desemprego seria mais causado por fatores exclusivamente econômicos (Honneth, 2007, p.93).

Tal apelo ganha ainda mais proeminência quando se comparam indivíduos em posições ocupacionais próximas, com formação e funções semelhantes, mas que se encontram em disparidade salarial, de benefícios ou nas chances de realização profissional. Dentro dessa delimitação, caem por terra quaisquer tentativas de justificação por meio do desempenho diferencial. Por esse ângulo, o paradigma produtivo, ao qual as formas de trabalho se aferram, é secundário. O elo entre reconhecimento e trabalho arrola a luta por redistribuição e direitos como cenário, visto que ele encarna uma maneira de expressar a eticidade das relações econômicas. Como substrato normativo, a hierarquia moral ocidental do trabalho é perpassada por lutas simbólicas que permitem definir o valor cultural de uma atividade laboral. Nas sociedades modernas, toda forma de labor constitui seu valor qualitativo de forma relacional, tendo como referência uma hierarquia moral na cultura. Um dos quesitos norteadores dessa hierarquia repousa sobre o prestígio das competências intelectuais envolvidas no desempenho de um trabalho. Normalmente, tais competências são mediadas por instituições acadêmicas de renome. Menciona-se, portanto, o prestígio das competências intelectuais a fim de não naturalizá-las, dado que todo trabalho envolve, em maior ou menor grau de complexidade e sofisticação, competências técnicas e intelectuais.

Em complementação a isso, se o valor relativo de uma realização profissional está calcado num consenso coletivo sociocultural, seria realista equalizar todas as ocupações sob a ideia de que seu valor técnico, estético, pedagógico ou outro poderia ser subsumido à luta simbólico-moral por sua definição? Ao com- 
pararmos ocupações localizadas em extremos verticais do espaço ocupacional, esse raciocínio parece se enfraquecer, pois o problema não pode ser apreciado como sendo apenas fonte de injustiça, mas também de acesso à capacitação, de incorporação de capital cultural especializado, e de empoderamento produtivo.

De modo geral, o arquétipo produtivo-normativo da teoria do reconhecimento é o fordismo e a sociedade salarial, cuja divisão do trabalho se situa na clara delimitação operacional entre planejamento de finalidades práticas e execução de tarefas. Sua contrapartida é baseada no acordo de organização de categorias profissionais, contratos de longo-prazo e assalariamento. As relações profissionais devem ser, portanto, reguladas, elegendo-se a redistribuição como paradigma de justiça. $\mathrm{O}$ estabelecimento do taylorismo-fordismo como setor dominante se deu no âmbito da produção de mercadorias em massa, cuja baixa intensidade de inovação, comparada com as vanguardas produtivas (cf. Unger, 2001), por exemplo, estabeleceu não apenas a organização coletiva do trabalho por meio de categorias profissionais, mas, notadamente, a negociação por direitos trabalhistas como pano de fundo das conquistas sociais. Ela também se transformou no enquadramento e no paradigma laboral bá-

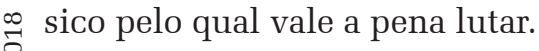

กิ Assim, o regime de trabalho flexível pró-

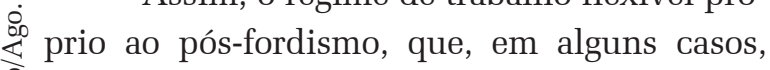
assume os moldes do novo espírito do capitalismo (cf. Boltanski; Chiapello, 2005), quase sempre é transcrito como narrativa da "perda de reconhecimento", "desprofissionalização" (Honneth, 2008, p. 47), ou "erosão da dignificação" (cf. Voswinkel, 2013). De fato, esse diagi nóstico é acertado para ocupações e postos nascidos no setor de serviços, funcionando como um braço administrativo do setor industrial de produção de mercadorias em massa. Contudo, a tese da "erosão da dignificação" e da "desprofissionalização" se enfraquece quando explicam as vanguardas produtivas (cf. Unger, 2010a): são indústrias nas quais a hierarquização entre concepção e execução, faculdades analíticas gerais e especialização seletiva não se divorciam de maneira tão cristalina.

A pujança heurística da teoria do reconhecimento revela-se em seu diagnóstico do estado presente da estrutura social, contraposto ao aprofundamento de aprendizado coletivo e político baseado na categoria de reconhecimento. Conquanto o conceito de aprendizado coletivo cumpra uma função teórica precípua, raramente se torna objeto de reflexão prática e da imaginação programática e institucional, permanecendo um ideal conceitual regulatório e analítico.

Se a desestabilização do reconhecimento institucionalizado, isto é, das relações laborais reguladas, reenvia à incerteza e ao oportunismo, a flexibilidade produtiva pode apenas significar subjugação, sendo incapaz de ensejar novas configurações organizacionais do trabalho. Em suma, a crítica normativa da ordem existente admite, assim, sua predileção por laços de solidariedade recíproca no longo prazo, reais, por oposição ao modo individualizado e oportunista, cujo resultado final não passa da própria instrumentalização do reconhecimento. O reconhecimento só se realiza plenamente através da estabilização de interações (institucionalmente mediadas) baseadas na reciprocidade. A precariedade do trabalho corresponde justamente à geração de incerteza e instabilidade de expectativas subjetivas e condições objetivas.

No entanto, por não delinear suficientemente bem a dinâmica conceitual entre as formas efetivas de reconhecimento e o marco produtivo e político histórico (fordismo-taylorismo e a social democracia europeia) que as ampara, a teoria do reconhecimento finda, em certo sentido, por fundir os dois. Essa indeterminação entre a definição das formas do reconhecimento laboral e seu enquadramento produtivo e institucional deixa em aberto um campo de reflexão normativo e programático, ao endossar tacitamente o paradigma da social-democracia e o modelo fordista de organização do trabalho industrial. 
Por marco produtivo, não abarcamos apenas o patamar técnico e material de uma cultura, mas também, por exemplo, seu regime de contratos, propriedade, crédito, alcance e poder de mercado. Em vista disso, esse caminho intelectual coloca em evidência a relação entre reconhecimento e estabilidade profissional, legada pela social-democracia, sem, no entanto, discutir a fundo as contradições internas às formas institucionais de organização que a abrigam, ou tensioná-las com modelos alternativos.

Decerto, se, por um lado, a social-democracia contribuiu enormemente - via redistribuição e regulação da especulação e das relações de trabalho - para a construção do patamar material, simbólico-cultural e moral de dignidade da classe trabalhadora europeia, o que é, sem dúvida, extremamente relevante, ela, por outro, encontrou dificuldades em democratizar reais oportunidades de mercado, alterando pontualmente posições relativas de classe. Concentrou-se, então, muito mais numa política de mitigação reajustada do que na transformação social via democratização das oportunidades de mercado e de produção. Foi preservada a intervenção do Estado como medida principal de contenção e limitação dos interesses privados e manteve-se o corporativismo partidário das minorias organizadas como arranjos institucionais cardeais (Teixeira, 2015, p. 58).

Em seguida, esse problema teórico torna-se mais grave em decorrência de não tomar, como fim de reflexão prática e comparativa, alternativas de organização da economia de mercado, para além do fordismo-taylorismo. Daí a correspondência sobreposta entre ordem produtiva da sociedade salarial, da social-democracia e uma forma de reconhecimento mais próxima da verdadeira.

Honneth (2007, p. 89) já havia indicado a dependência do poder heurístico formal do conceito de reconhecimento e sua aderência a etapas históricas concretas nas sociedades humanas. Nessa elucubração, nem os arranjos institucionais de tais etapas e nem as condi- ções intelectuais de sua superação prático-normativa se tornam problematizados. Por não delimitar tais zonas a contento, a configuração existente das formas de trabalho - assim como os arranjos institucionais e produtivos que a ela subjazem - não se torna objeto do pensamento teórico-programático, ensejando sua própria superação paulatina e gradual. Assim, o pensamento programático permitiria enxergar as aporias e confluências entre (neo)liberalismo florescente e social-democracia.

Se a noção de crítica imanente arrola, como pressuposto, a revisão daquilo que o funcionamento convencional da estrutura social promete, mas não realiza, isto é, uma recuperação de cláusulas do acordo, com vistas à universalização radical de potenciais morais (propósito da democracia), sem aliar tal esforço à imaginação alternativa de arranjos institucionais e organizacionais, corre-se o risco de permanecer dentro da espiral do pensamento político convencional, recaindo na humanização de injustiças existentes. Encerrada no aparato do ideário programático dominante de um contexto formativo (Unger, 2001, p. 58-59), a regulação e a desregulação do mercado de trabalho são faces de versões de uma ordem estabelecida.

\section{TRABALHO E PRODUTIVISMO}

O conceito de trabalho defendido pela teoria do construtivismo institucional de Mangabeira Unger articula, de modo claro, a relação entre formas ocupacionais específicas e seu lugar em determinada maneira de organizar a força de trabalho (cf. Unger, 2001). Essa associação conforma, portanto, uma esquematização contingente da divisão do trabalho, refletindo igualmente o arranjo histórico de instituições econômicas. A conexão entre a organização técnico-material do trabalho, o patamar de progresso material e a intensificação da experiência social do indivíduo é arrolada como pano de fundo. Subjacente a essa associação, repousa um potencial prático-normati- 
vo do trabalho, similar ao percebido por Honneth (1980, p. 186), visto que a atividade laboral permite tornar competências e capacidades conscientes, abrindo espaço para um potencial de aprendizado e um incremento produtivo.

Sua indagação é, menos, recuperar a afinidade entre solidariedade, regulação e valor sociocultural do trabalho, do que a afinidade entre inovação e trabalho. Não há como promover inclusão sem um novo projeto produtivo. Entre as duas formas principais disponíveis, na atual divisão do trabalho produtivo, encontram-se três tipos: a) o trabalho flexível, intenso em inovação e conhecimento, presente em setores de vanguarda produtiva; b) trabalho de planejamento, de um lado; c) trabalho de execução de outro. A primeira forma é encontrada em empresas de vanguarda e setores não competitivos do mercado, ou seja, em setores embrionários, financiados seja no âmbito privado, seja no público. O que interessa a Unger é que as vanguardas produtivas - nas forças militares, em setores de ponta da engenharia, de nanotecnologia, da cibernética, da física e etc. - combinam ou acumulam o uso de alta tecnologia e de práticas experimentais de organização do labor. Já os tipos de trabalhos indicados nas alíneas b e c situam-se, em sua esmagadora maioria, no setor industrial e de serviços

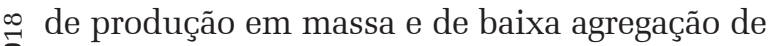
práticas laborais arrojadas, além de sua dema\& ioda segmentação e especialização.

A dinâmica entre inovação e trabalho ocupa a proa da economia política de Mangabeira Unger, pois tensiona a acepção de trabalho alienado, corrente na teoria social i. europeia. Para Marx, a categoria trabalho vivo abarcava três significados: a) o epistemológico; i b) o de formação da consciência política revolucionária; c) o econômico, como parte fundamental da engrenagem do ciclo de valorização do capital. Se os dois primeiros significados carregam, em seu bojo, um sentido "antissistêmico" (transformador), o terceiro, sob o conceito de trabalho abstrato, explica a estrutura profunda do modo de produção capitalista.
Unger tensiona a primeira e a terceira conjecturas. Elas visam a recuperar um ideário em Marx: a relação entre emancipação e progresso técnico-material. O embotamento desse paradigma tem seu ápice na teoria da ação comunicativa de Habermas (Honneth, 1980, p. 217-222), cuja distinção entre ação instrumental do trabalho, como mera reprodução material, e liberação social mediante ações que visam ao entendimento é seu representante mor. De uma vez por todas, progresso técnico-material e emancipação são extirpados um do outro, ou seja, tornam-se caracterizados pela oposição entre trabalho e interação. Para teorias sociais germinadas em países já localizados no pico do desenvolvimento tecnológico e industrial, esse paralelo conceitual talvez encontre correspondência na realidade; para países atrasados, nem tanto.

Ademais, o próprio conceito de razão instrumental comporta uma importante dualidade: de um lado, ela consiste na atividade de reaplicação circular de conhecimentos, visando à maximização de eficiência, à utilidade, ao domínio científico de processos produtivos, estando simultaneamente aliada a práticas experimentais controladas. De outro, ela pode significar a mera repetição, a execução de tarefas robotizadas, planejadas pelos administradores da grande firma. Essa segunda corrente foi largamente abraçada pela teoria crítica, obscurecendo a primeira.

A ideia de uma categoria epistemológica de trabalho corresponde não apenas à construção da consciência das próprias faculdades, competências humanas e produtivas, mas ao processo de aprendizado no qual o trabalho vivo não se torna mero refém da máquina, auxiliando no enriquecimento da vida psíquica e social. Assim, para Unger, o elo entre progresso material, inovação e História diz respeito ao fomento e à construção de formas mais complexas de trabalho, na medida em que um arranjo produtivo reflete tanto sua orientação com relação a um projeto nacional quanto alude a um estado histórico das formas laborais reproduzidas. No 
limite, um arranjo produtivo de nações dominantes estimula, no geral, formas mais complexas de trabalho inovador, incrementando e diferenciando sua divisão do trabalho interna. Admite, dessa maneira, experiências inusitadas de cooperação, além de burlar divisões disciplinares estéreis. Isso não significa, no entanto, a inexistência rupturas e fissuras.

Isso posto, qualquer atividade laboral engendra um contexto prático pedagógico e, por vezes, teórico, no qual o instrumentário conceitual e prático pode ser revisitado. Com o acoplamento entre razão instrumental, tomada em seu corolário repetitivo, tal contexto é obnubilado. Ao aduzir o elo entre inovação e trabalho, Unger disponibiliza um conceito epistêmico de trabalho, que pode servir de critério interno à divisão do trabalho. Honneth (1980, p. 190191) procurava o ideal do trabalho artesanal como caminho para recuperar uma categoria não estranhada de trabalho: uma forma laboral que apresentasse menor grau de determinação externa de procedimentos, trazida pelo taylorismo-fordismo. Em grandes indústrias de produção em massa, práticas de resistência em local do trabalho representam um esforço de cooperação e pretensão ao controle autônomo do processo produtivo. Para o filósofo alemão, isso configuraria a tessitura normativa do trabalho, invisível à ação comunicativa.

O problema é que a forma artesanal do trabalho, salvo exceções, não é uma exigência estrutural da divisão do trabalho, o que o faz abandonar essa investigação (Honneth, 2008, p. 52). O contrário acontece com a categoria trabalho flexível de Unger. Ela não só é uma demanda interna à estrutura normativa das ocupações como sua ponta de lança. Para o trabalho artesanal, o espaço de aprendizado se desenvolve indutiva e sensivelmente, ou seja, rente ao instrumento, quase numa relação orgânico-sensorial com ele (Ibidem, p. 195). Já o trabalho flexível exige não apenas o improviso indutivo, mas a reaplicação crítica e corretiva de conhecimentos teóricos, práticos e de pesquisa, de maneira a tornar estruturante um contexto de aprendizado mútuo e individual. Seu contexto pedagógico aprofunda a dialética entre faculdades analíticas gerais e especialização seletiva. Com essa abertura experimental controlada, a especialização exorbitante, tendendo a segmentação fragmentária, cede lugar à cooperação interdisciplinar. Outro aspecto é sua relação com a máquina, que não mais subjuga o trabalhador diretamente, mas o liberta das atividades repetitivas, permitindo-lhe desenvolver as tarefas que ainda não são passíveis de serem resumidas numa fórmula.

Para o pensador anglo-brasileiro, a reinvenção da divisão do trabalho se torna factível no momento em que se analisa e critica o modelo consagrado da fábrica de alfinetes (cf. Unger, 2010a). Seu ponto principal é a relação entre agente produtor, sua especialidade e a máquina. No modelo produtivo da fábrica de alfinetes, a organização do trabalho reforça o domínio da máquina sobre o trabalho, dado que ela torna o trabalhador sua extensão ou mero operador. Assim, ele não faz nada de diferente dela, acabando por desempenhar um trabalho repetitivo, no domínio parcial dos conhecimentos para operar ou reparar a máquina. O ideal da linha de montagem, com suas funções rigidamente especializadas na distribuição de tarefas, é o que está em jogo aqui. Não é por acaso que a organização do trabalho, através da fábrica de alfinetes, foi percebida como protótipo de uma sociedade altamente disciplinada e repressiva, na qual o trabalho conforma um instrumento de sacrifício dos prazeres individuais em prol da futura riqueza coletiva (Ibidem, p. 101).

Imaginar uma nova organização do trabalho, tomando seu arranjo efetivo, é pensar a estrutura de maneira contrafactual. O plausível é convizinho do existente. Sob esse prisma, imaginemos um enquadramento alternativo da interação entre trabalhador e máquina dentro do qual ele não mais serve como extensão de suas tarefas automatizadas, mas programa-as numa fórmula. Tão logo incorporado esse algoritmo nas máquinas, elas farão a parte repetível do trabalho. Por conseguinte: 
A parte ainda não repetível das atividades - aquela para a qual não temos fórmulas e, portanto, nem máquinas - é o domínio da inovação, a linha de frente da produção. Nesse reino, a produção e a descoberta tornam-se mais ou menos a mesma coisa. Buscamos aí organizar as atividades produtivas para que se tornem uma imagem visível e coletiva, e o instrumento de nosso pensamento experimental (Unger, 2010a, p. 101-102).

O ideário à frente da produção não seria mais, de acordo com Unger, o utilitarismo raso da fábrica de alfinetes, relegando o contexto experimental e de aprendizado no local de trabalho para segundo plano, mas o de abrir caminho ao aprendizado coletivo, para que o tempo, com o lado reprodutivo da atividade laboral, possa ser poupado.

Isso posto, o fortalecimento de descontinuidades hierárquicas na divisão entre supervisão e execução torna-se um imperativo. Honneth já havia apontado como, mesmo sob uma organização do trabalho do tipo taylorista-fordista, trabalhadores exibiam não apenas o afã, mas igualmente as habilidades para subverter positivamente os procedimentos que lhes foram impostos. No entanto, a organização excessivamente hierárquica da produção acachapa o florescimento desse contexto pedagógico. Desse modo, permitir certa experimentação controlada - fora de procedimentos pré-esta-

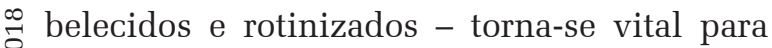
: empoderar novamente o trabalhador, tornando o exercício da profissão relativamente aberto. O desenvolvimento de novas zonas de aplicai ção de conhecimento torna-se concomitante à atividade producente. A própria máquina dedicada à inovação não tem uma finalidade completamente predeterminada.

A cooperação seria, aqui, um apanágio fundamental da performance laboral, abrindo a possibilidade de compreensão das diferentes etapas do processo produtivo, por evitar a robotização do trabalhador preso numa gama limitada de tarefas (Honneth, 2008, p. 62-63; Unger, 2010a, p. 103). A reflexão sobre dispositivos institucionais que reforcem esse aspecto resultaria não apenas em inovação, mas na consubstanciação do elemento propriamente orgânico da solidariedade presente na divisão moderna do trabalho. Ela não apenas beneficia a percepção coletiva do processo de aprendizado laboral, mas auxilia a incorporação de habilidades adjuntas a um tipo de desempenho especializado. A especialização deve ser vista como aprofundamento seletivo. No entanto, a cooperação não deve ser, nem no âmbito administrativo e nem da fabricação, substituída por uma forma de "trabalho em equipe", cuja finalidade é destacar decisões operacionais de magnitude média e as de grande porte, isto é, estratégicas, legadas aos altos quadros. Cria-se, então, a falsa sensação (aos escalões intermediários e inferiores) de coordenação e descentralização decisória, reforçando a disparidade vigente (cf. Maciel; Torres, 2007).

Uma das características centrais do regime taylorista-fordista é seu intransigente encaixe entre desempenhos funcionais, qualificação e especialização. Além disso, alia uso intensivo de mão de obra à produção tecnológica rudimentar. No regime de generalização de formas vanguardistas de produção, com a incorporação de práticas de produção além das fronteiras da alta tecnologia e de setores intensivos em conhecimento científico, valoriza-se a dinâmica entre especialização e competências gerais. A especialização deve ser vista como aprofundamento seletivo e não como fragmentação do conhecimento. Ela favorece a inovação porque permite uma reaplicação inusitada e o florescimento de um contexto de aprendizado dentro do ambiente de trabalho. Segundo Mangabeira Unger, mesmo o fenômeno da precarização do trabalho, em setores da indústria e dos serviços, funcionaria, em certo sentido, como revérbero da decadência do taylorismo-fordismo (fábrica de alfinetes) como organização do trabalho, posto que admite regime de contratações descentralizadas e desvantajosas, por depreciar o trabalho vivo. Como arquitetura organizacional do trabalho e formação profissional, as vanguardas produtivas já são uma realidade no cenário 
mundial, mas sua ligação com outros setores da economia nacional é lábil e fragmentária. Ademais, as novas configurações do setor vanguardista, orientadas por uma economia do conhecimento, ainda constituem uma realidade de pequenas elites intelectuais espraiadas pela sociedade global. Esse regime laboral ainda exibe baixa capacidade de inclusão da força de trabalho como um todo.

De acordo com Unger, a conexão entre vanguardas produtivas, setores econômicos emergentes e o setor de produção de mercadorias em massa é nodal. Nesse escopo, faz-se imperativo que o Estado fomente novos agentes econômicos em ascensão, diversificando os modos de acesso a mercados. Portanto, trata-se da equipagem de pequenas empresas, que ainda não gozam plenamente de maquinário de ponta, com práticas científicas avançadas, inclusão no sistema financeiro e poder organizacional. Contudo, tais empresas já exibem enorme potencial inovador.

Daí o papel empreendedor do Estado (por oposição a seu papel regulador) na alavancagem desses segmentos, dado que o autor os enxerga como suportes históricos e econômicos estratégicos do desenvolvimento produtivo e não mais como a retaguarda da retaguarda produtiva. Embora não conformem a vanguarda produtiva, Unger enxerga, nesse segmento social, uma enorme aptidão para ocupar essa posição. Eis a relação entre produtivismo e inclusão. No Brasil, tais setores se localizam em pequenas indústrias e iniciativas agrícolas em classes sociais que comumente não partilham do imaginário cultural burguês.

A aptidão enxergada em tais negócios de pequeno porte ressoa em práticas produtivas experimentais de inovação. Por sua vez, tais práticas são observáveis na camada empreendedora da nova classe trabalhadora, denominada como batalhadores (Unger, 2010b). Nela, verifica-se, ao contrário dos setores localizados na periferia do pequeno comércio informal, a presença da unidade produtiva. Enquanto, pelo menos na região Nordeste, as iniciativas de microcrédito produtivo alvejam predominantemente o pequeno comércio urbano (Credi Amigo, 2013), cuja concatenação de atividades é fragmentada e instável, nem sempre o mesmo acontece com tanta veemência na pequena indústria. Não é arbitrário que o acesso à pequena fábrica enlace um fio condutor de trajetórias profissionais que, do contrário, permaneceriam fragmentadas (Medeiros, 2010). Ela confere um sentido e amarra saberes adquiridos, pois aproxima homem e máquina de modo criativo.

$\mathrm{O}$ acesso à unidade produtiva tem, para o púbico em questão, forte conotação positiva, pois proporciona unidade mínima entre atividades laborais, além de especialização da trajetória profissional (proporcionando-lhe uma ordenação relativa) e inovações relevantes em maneiras de fabricação. Elas ocorrem em três níveis: a) aperfeiçoamento de um arranjo geral de instrumentário por meio de correções em funções específicas; b) composição e mescla inusitada de objetos, dando origem a um novo; c) "mudança de domínio" e aplicação a serviço de nova finalidade (Medeiros, 2010, apud Sennett, 2008, p. 219). Nota-se que os dois últimos níveis sequer poderiam germinar sem um alargamento dialético entre competências técnicas gerais, específicas e cooperação. Ao manter uma estrutura organizacional e de empregabilidade mais próxima, as pequenas e médias empresas estão mais aptas ao ingresso no setor vanguardista do sistema produtivo. Essa mediação ganha especial vulto estratégico, porquanto o ciclo de inclusão, representado pelos governos Lula e Dilma, não foi capaz de realizar: privilegiou-se a democratização do consumo, mas não a dos instrumentos verdadeiramente competitivos do mercado.

Com isso, Unger advoga que a economia de mercado deve não apenas organizar-se em torno da seletividade pela eficiência, mas pela diversificação de bens e serviços. Coordenação, cooperação e competição tornam-se conceitos relacionais. Para tanto, faz-se necessário romper com oposições rígidas entre livre comércio e protecionismo, bem como entre 
livre iniciativa e intervencionismo. Esse é o caminho para produzir uma robusta vantagem comparativa. As duas correntes sofrem de um mesmo mal de origem, que contamina o contexto formativo: uma tem visão determinista do Estado como agente "ineficiente" na alocação de recursos e capital; a outra, do mercado como destinado e dedicado univocamente à exploração das classes dominadas pelas dominantes. Do mesmo modo, seleção e diversificação são pares dialéticos os quais devem guiar a imaginação programática da economia (Unger, 2010a, p. 112). Aliás, ela deve consistir na tônica do diálogo entre vanguarda e retaguarda produtiva. Nas obras de economia política de Unger, a retomada de um contexto laboral pedagógico, orientado pela inovação - por meio da descentralização produtiva -, se concilia com um pensamento econômico que se despe de seu naturalismo conceitual intrínseco.

Aliado a esse fito, o sistema educacional deve romper com sua excessiva procedimentalização, o que culmina no ensino enciclopédico raso. Outra problemática diz respeito à forma do aprendizado, quando ligado ao desempenho com base num individualismo atomista, raramente capaz de gerar iniciativas de cooperação. Em lugar de sacralizar os cânones, o sistema de ensino deveria se dedicar ao ensino analítico, $\stackrel{\infty}{\rightleftarrows}$ tendo como pilar o contraste relacional de perspectivas intelectuais contrárias, ao invés de sua \& reconciliação fragmentada e descontínua.

Apesar da efetiva democratização escolar ocorrida no cenário europeu do pós-guerra, além da eliminação do trabalho infantil, prática corriqueira na passagem da manufatura para $\dot{2}$ a indústria de base, a social-democracia não rompeu com o ensino enciclopédico. Ele logra, i sobretudo, manter vantagens relativas historicamente cristalizadas pela herança familiar de classe. O estudo A reprodução, de Pierre Bourdieu e Jean-Claude Passeron (1970), trata exatamente disso, embora os autores estejam limitados por uma análise sociológica da reprodução, na qual a naturalização do contexto formativo impede a contraposição de finalidades alternativas para o sistema escolar, para além da reprodução de esquemas cognitivos valorizados pela cultura legítima burguesa. A aliança entre ensino enciclopédico, tomado como forma pedagógica por excelência, e uma teoria geral da violência simbólica é o ponto nodal do livro. O sistema educacional estaria fadado à reprodução de esquemas de pensamento inconscientes, sendo aqueles que os dominam, acima de tudo nas humanidades, habilitados a identificar os padrões dos jogos estilísticos e intelectuais do campo acadêmico. Por de trás dessa estrutura organizacional institucional aparentemente meritocrática - pois repousa em procedimentos, exames e avaliações impessoais que se impóem a todos -, persiste o acesso privilegiado e precoce das famílias de classes burguesas à cultura letrada. Sob esse ângulo, não existe talento individual naturalmente concedido. A violência simbólica relega esse contexto familiar prévio às sombras, impedindo a percepção imediata dessa injustiça.

Mangabeira Unger ainda trata da relação entre família e classe social. No prefácio ao livro: Batalhadores brasileiros (Unger, 2010b), encontramos uma pista de sua imaginação programática nesse âmbito: à ralé, que constitui o "núcleo duro" da pobreza, deveriam ser destinadas políticas que estimulassem a organização familiar e a auto-organização comunitária, o Estado assumindo até mesmo familiares, quando necessário. Já os batalhadores deveriam ser o alvo de políticas de capacitação profissional e escolar (Ibidem, p. 11).

A família não deve ser apreendida apenas a partir de uma forma de manifestação ou configuração histórica e empírica particular, mas entendida na qualidade dos elos afetivos que se estabelecem entre os papéis de cada membro. Ao contrário do que normalmente se pensa, a família está intimamente conectada com o Estado e com o mercado de trabalho, além de cumprir duas finalidades interligadas, percebidas por Bourdieu e Passeron (1970) e Honneth (2012, p. 150-154): a) ela é responsável pela socialização primária, isto é, aquisição 
de esquemas comportamentais que operam no nível pré-reflexivo e cognitivo; b) cabe a ela a função moral de constituição bem sucedida da identidade individual por meio de autoestima, ou seja, uma autorrelação prática positiva de si. A socialização familiar positiva é, em suas etapas primordiais, operada pelo cuidado afetivo e complementada por uma socialização disciplinar em suas fases subsequentes. No tocante a disposições, capacidade de concentração e disciplina, ela forma, por exemplo, duas competências pré-reflexivas que proporcionam o acesso às formas mais complexas de aprendizado intelectual, trazendo, em seu bojo, uma relação ativa de planejamento com o tempo. O fato é que autoestima, disciplina e concentração são pré-condições do aprendizado. A autoestima se converte na confiança para insistir e aprender com os erros. São esses, portanto, atributos essenciais da personalidade, necessários não apenas à política de capacitação, mas ao fortalecimento da subjetividade e à expansão de formas diferenciais e dialéticas de consciência.

O cuidado afetivo se se inicia na simbiose narrada por Honneth, em apoio à obra de Winnicott (Honneth, 2012, p. 159), na qual a boa formação da personalidade depende da preservação desse compartilhamento simbiótico (symbiotische Gemeinsamkeit) entre mãe e criança. Essa fase é fundamental para a formação psicossocial do indivíduo. Contudo, sociologicamente, ela pressupõe manter a mãe no lar, seja através de uma divisão do trabalho doméstico, seja obtendo uma licença maternidade, caso o responsável tenha um emprego. Com uma configuração quase sempre monoparental (a mãe), laços instáveis e um regime informal ou de exploração extensiva, a organização familiar da ralé se vê fragilizada diante dessas circunstâncias.

A identificação da desagregação familiar da ralé pode ser configurada em três desdobramentos categóricos complementares, que se encontram mesclados na realidade empírica: a) a violência doméstica; b) vigilância e raciona- lização cotidiana; c) estabilidade das relações familiares. A violência doméstica constitui um foco problemático, cujo efeito mais nefasto se dá por meio de abusos sexuais e espancamentos, sem que a vítima consiga reconstruir suas motivações. Assim, a punição violenta não tem carga disciplinadora do corpo com relação à violação da regra, mas forma a tessitura comunicativa entre pais e filhos. Esse tipo de socialização sadomasoquista de suplício do corpo se contrapõe à educação disciplinar e afetiva, baseada em punições comunicativas disciplinares e, em parte, no uso disciplinar da violência. Ainda assim, mesmo nos casos mais extremos de socialização sadomasoquista, há a tentativa, muitas vezes incipiente, de se instaurar uma esfera discursiva. No entanto, ela geralmente não é o contexto formador e estruturante do cotidiano familiar. A tensão entre uma prática sadomasoquista e a esfera discursiva deve ser usada para robustecer a segunda em detrimento da primeira.

A segunda problemática a ser objeto da reflexão programática é a vigilância. Ela é correlata da racionalização cotidiana e do encerramento relativo da família, contrabalançando-se, no caso-limite, contra o destino da delinquência. Bernard Lahire explorou a afinidade eletiva entre desempenho escolar nas classes trabalhadoras francesas, racionalização do cotidiano (controle e a compartimentação de horário e atividades) e punição discursiva (cf. Lahire, 2012). Há uma íntima relação entre os dois últimos elementos: geralmente, a punição violenta oculta certa permissividade, não havendo, então, a antecipação à violação. Esse tipo de punição gera baixa confiança na interação. O resultado é não apenas menor adesão de quem obedece à regra, mas também menor grau de reflexividade e de compreensão. A lábil vigilância é mais comum quando se perpetua uma tensão entre a fixação temporal de dedicação à família e a esfera laboral precária. Muitas vezes, por não contar com redes familiares de apoio, a ralé e, parcialmente, as camadas inferiores precarizadas dos batalhadores se 
colocam em posições mais vulneráveis de desagregação familiar.

Já para os batalhadores, como observa Unger, o problema se estriba em políticas educacionais e profissionais de capacitação. Para boa parte dos jovens das classes populares, seu destino se pauta pelo ingresso em empregos formais precários (telemarketing, caixa de supermercado, office boy etc.) ou informais desqualificados.

Particularmente, a tensão do ingresso (por vezes ligado não de modo direito às urgências econômicas efetivas) nessas áreas precarizadas do mercado de trabalho combina com um contexto familiar em que há uma perda de status da escola perante a família e a comunidade local. Certamente, a qualidade do ensino também contribui para fortalecer ou enfraquecer essa percepção. Comumente, a valorização familiar de se tornar um trabalhador "a qualquer custo" incute o sacrifício do planejamento educacional. É preciso desconstruir essa visão. Vimos, com Bourdieu, como a forma pedagógica escolástica ou enciclopédica do ensino privilegia um modo de transmissão comunicativa alheia a qualquer contexto prático imediato. Isso porque as classes dominantes não lutam pelo ingresso nesses dois setores precarizados da hierarquia do trabalho, de modo que tiram proveito do acesso precoce à cultura letrada,

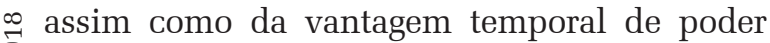
se dedicar à sua incorporação e estender sua $\stackrel{8}{8}$ trajetória educacional. A lida com essa tendência, na trajetória dos batalhadores, institui um i ambiente cognitivo particular, já que a ligação afetiva com o aprendizado não pode se desacoplar completamente do entendimento de suas i. aplicações e serventias práticas mais ou menos imediatas. Por conseguinte, seu modo de apreniz dizado se distancia do puro diletantismo.

De modo geral, políticas de capacitação e proteção social dependem dos problemas que se apresentam em cada estrato social. Enquanto, para a ralé - carente dos mecanismos de inclusão básicos -, fazem-se necessárias políticas públicas mais voltadas para a proteção social e redistribuição, as circunstâncias dos batalhadores levantam indagações mais desafiadoras ao pensamento programático, porquanto envolvem a democratização do poder produtivo e educacional.

Concluímos que as duas correntes de pensamento anseiam por um conceito de liberdade por meio da prosperidade da vida pública: a teoria do reconhecimento, com a noção de intersubjetividade normativa e comunicativa, e o construtivismo institucional, concatenando a volição individual a suportes e arranjos institucionais alternativos.

O esforço de contrastar as duas perspectivas objetiva esclarecer as ênfases das duas correntes de teorias do trabalho. Nem a teoria do reconhecimento nega completamente o problema produtivo, muito menos o construtivismo institucional rechaça que trabalho deva promover inclusão. Se, por um lado, a teoria do reconhecimento logra apresentar os fundamentos morais do trabalho e da economia, mostrando como a esfera produtiva não opera unicamente sob a égide da eficiência e da produtividade, o construtivismo institucional se obstina em demonstrar como o engrandecimento da vida cotidiana não prescinde de um projeto produtivo alternativo, imaginando renovadamente os arranjos institucionais que definem as chances de vida dos indivíduos e as formas laborais (mais complexas) que irão desempenhar. Em última análise, não há como generalizar progressivos padrões de reconhecimento sem construir uma estrutura produtiva e econômica complexa.

Um aspecto destoante das duas abordagens teóricas é a maneira como tensionam a crítica da ordem social vigente e a transformação. Nesse particular, a teoria do reconhecimento, cujo fundamento teórico é a ideia de uma moralidade substancial - baseada na noção de boa vida socialmente compartilhada -, admite explicitamente (mais do que as teorias contemporâneas do poder) o elo entre crítica e transformação. No entanto, ao não incluir o pensamento programático nessa agenda de indagação, acaba por tornar nebulosa a relação entre o nível abstrato e o particular. Dito de 
outra forma: carece de uma demarcação mais límpida entre reconhecimento e suas formas organizacionais práticas possíveis, contingentes e historicamente fundadas.

Por fim, se os teóricos do reconhecimento acusam a necessidade de fortalecer laços estáveis de solidariedade, por meio da conquista de direitos e inclusão na sociedade salarial, é mister complementar e aprofundar o debate sobre a regulação do mercado de trabalho junto à reconstrução dos critérios norteadores da economia política contemporânea. Para tanto, também é preciso questionar o contexto formativo que ampara um estado historicamente contingente da divisão do trabalho. Concomitante à política do reconhecimento de formas laborais precarizadas, ou mesmo do pressuposto normativo do mercado, segundo o qual todos têm direito de contribuir de maneira produtiva e valiosa à reprodução material da sociedade, arrola-se, como tarefa, imaginar um conjunto de reflexões programáticas que poderiam estimular uma organização do trabalho alternativa, que transcenda a tradicional fábrica de alfinetes, mesmo em sua versão regulada, consagrando a construção de uma estrutura econômica e produtiva complexa.

Recebido para publicação em 04 de junho 2017 Recebido em 23 de junho de 2018

\section{REFERÊNCIAS}

ANTUNES, R. Adeus ao trabalho? São Paulo: Cortez; Unicamp, 2000.

BOLTANSKI, L.; CHIAPELLO, E. The new spirit of capitalism. $2^{\text {a }}$ edição. New York: Verso, 2005.

BOURDIEU, P. Algérie 60: structures économiques et structures temporelles. Paris : Les Éditions de Minuit, 1977.

BOURDIEU, P.; PASSERON, J. C. La reproduction : éléments pour une théorie du système d'enseignement. $1^{\mathrm{a}}$ edição. Paris: Éditions de Minuit, 1970.

DUTRA, R. Diferenciação funcional e a sociologia da modernidade brasileira. Política \& Sociedade, Florianópolis, v.15, n. 34, set./dez. 2016.

HONNETH, A. Arbeit und instrumentales Handeln. Kategoriale probleme einer kritischen gesellschaftstheorie. In: Arbeit, handlung, normativität: theorien des historischen Materialismus 2. Erste Auflage, Frankfurt am Main: Suhrkamp Verlag, 1980.
Kampf um Anerkennung, 7 Auflage. Frankfurt am Main: SuhrkampVerlag, 2012.

Trabalho e reconhecimento: tentativa de uma redefinição. Revista Civitas, Porto Alegre, v. 8 n. 1, p. 4667, jan./abr. 2008.

Reconhecimento ou redistribuicão? A mudanç de perspectivas na ordem moral da sociedade. In: SOUZA, J.; MATTOS, P. (Orgs.) Teoria crítica no século XXI. $1^{\text {a }}$ edição. São Paulo: Editora Annablume, 2007.

KÜHN, T.; WINTZEL, A. Die ArbeitskraftunternehmerThese aus berufsbiografischer Perspektive. In: PONGRATZ, H.J.; VOSS, G.G. (Hrsg.) Typischen Arbeitskraftunternehmer? Befunde der empirischen Forschung. Berlin: edition sigma, 2004. S. 229-253.

LAHIRE, B. Tableaux de famille: heurs e malheurs scolaires en milieux populaires. 1a edição. Paris: Seuil, 2012.

MACIEL, F; TORRES, R. Trabalho, reconhecimento e democracia: aplicando teorias de vanguarda ao contexto periférico. In: SOUZA, J.; MATTOS, P. (Orgs.) Teoria crítica no século XXI. $1^{\mathrm{a}}$ edição. São Paulo: Editora Annablume, 2007.

MACIEL, F. A nova sociedade mundial do trabalho: para além de centro e periferia? 1. Edição. São Paulo: Editora Annablume, 2014.

MEDEIROS, L. Populismo ou medo da maioria? Como transforma em tolice as razões da massa. In: SOUZA, J. (Org.). Os batalhadores brasileiros: nova classe média ou nova classe trabalhadora? $1^{\text {a }}$ edição. Belo Horizonte: Editora UFMG, 2010.

RELATÓRIO Anual Crediamigo. Banco do Nordeste (BNB). 2013. Disponível em: www.bnb.gov.br. Acesso em: 20. 07. 2013.

SENNETT, R. A corrosão do caráter: conseqüências pessoais do trabalho no novo capitalismo. 13. ed. Rio de Janeiro: Editora Record, 2008.

SIMMEL, G. Philosophie des geldes. Erste Auflage, Köln: Anaconda Verlag, 2009.

SIMMEL, G. Über die soziale differenzierung. Gesammte Ausgabe (Aufsätze 1887 bis 1890), Hrsg. von Otthein Rammstedt, Band II Hrsg. Von Heinz - Jürgen Dahme, Erste Auflage. Frankfurt am Main: Surhkamp, 1989.

UNGER, R. Os batalhadores e a transformação do Brasil. In: SOUZA, J. (Org.) Os batalhadores brasileiros: nova classe média ou nova classe trabalhadora? $1^{\mathrm{a}}$ edição. Belo Horizonte: Editora UFMG, 2010b.

False necessity: anti-necessitarian social theory in service of radical democracy. 1st. London/New York Verso, 2001

. A reinvenção do livre-comércio: a divisão do trabalho no mundo e o método da economia. $1^{\mathrm{a}}$ edição. Rio de Janeiro: Editora FGV, 2010a.

VISSER, R. Para uma sociologia do dinheiro: investigação sobre habitus sobre habitus econômico de classe. 2015. 213 p. Tese [Doutorado] - Universidade Federal de Juiz de Fora.

VOSWINKEL, Stephan: anerkennung (in) der arbeit. Veränderungen und normative orientierungen; in: Die erosion von anerkennung. Soziologische und theologische perspektiven. Symposium der Evangelischen Akademie der Nordkirche, Hamburg, 28.11.2013. Evangelischer Pressedienst (epd) Dokumentation, n. 14, p. 4-10, 2013.

TAYLOR, C. Sources of the self: the making of the modern identity. $1^{\mathrm{a}}$ edição. Cambridge: Harvard University Press, 1989.

TEIXEIRA, C. S. Modos de explicar o Brasil: o estruturalismo sociológico de Florestan Fernandes e o construtivismo institucional de Mangabeira Unger. Revista Sinais Sociais, Rio de Janeiro, v. 10, n. 28, p. 55-79, maio/ ago. 2015. 


\section{HONNETH'S AND UNGER'S THEORIES OF LABOR: recognition and inclusive productivism}

\section{Ricardo Visser}

In this article two currents of social thought will be compared taking into account the concept of labor. On one side, the theory of recognition defines labor by its cultural and symbolic value, which is conceived in the Western moral hierarchy. Its paradigm is the wage labor and the regulation of contracts. On the other hand, the theory of institutional constructvism understands labor as a productive activity oriented by innovation. It tries to reconcile technical and material progress with the deepening of the social experience of the individuals.

KEY WORDS: Labor. Recognition. Institutional constructivism. Social theory.
LA THÉORIE DU TRAVAIL DE HONNETH ET UNGER: reconnaissance et productivisme inclusif

\author{
Ricardo Visser
}

L'article analyse deux écoles de pensée à partir de la catégorie de travail. En suite on ira analyser leurs contradictions internes. D’un côté, la théorie de la reconnaissance défine le concept de travail par sa valeur culturelle et symbolique, encerré dans l'hiérarchie morale occidentale. Son paradigme est la société salariale et la régulation des rapports profissionels par l'État. D'autre côté, le constructivisme institutionnel délimite la catégorie de travail entendue comme activité productive orientée par l'innovation. Son cadre théorique vise recuperer l'aliance entre le progrès téchinique, matérial et l'aprofondissement de l'expérience sociale des individus.

Mots-CLÉs:Travail.Reconnaissance.Constructivisme institutionnel. Théorie sociale. participou da pesquisa que resultou no livro Reproduktion sozialer Ungleichheit. Entre 2015-2016 atuou como gerente de projetos no Instituto de Pesquisa Econômica Aplicada (IPEA). Atualmente é pesquisador pós-doutoral na Faculdade de Direito da Universidade do estado do Rio de Janeiro (Uerj). Publicações recentes: A sociologia econômica de Simmel e Bourdieu: considerações para um programa de pesquisa. CIVITAS: Revista de Ciências Sociais (impresso), v. 17, p. 60, 2017; Significado e transformação das formas de capital: sobre a reprodução da desigualdade de classes na Alemanha. Revista Direito e Práxis, v. 08, p. 1694-1718, 2017; A socialização da família batalhadora. Revista Direito e Práxis, v. 07, p. 317, 2016. 